\title{
SKALA EMOTIONAL WELL BEING (EWB) BAGI MAHASISWA DI MASA PANDEMI COVID 19
}

\author{
Rosalia Dewi Nawantara ${ }^{1}$, Setya Adi Sancaya ${ }^{2}$ \\ Universitas Nusantara PGRI Kediri \\ rosaliadewi@unpkediri.ac.id
}

\begin{abstract}
Emotional Well Being (EWB) is an individual's positive feelings in living life including a sense of happiness and life satisfaction. The COVID-19 pandemic is an extraordinary event that has an impact on all lines of life. The education sector has not been spared the impact of the COVID-19 pandemic. The study from home appeal, which has been running for more than a year, continues to suppress the spread of Covid-19 cases. However, behind this policy, there are problems that arise regarding the emergence of several psychological problems experienced by students related to EWB. The purpose of this research is to develop an emotional well-being scale for students during the Covid 19 Pandemic. The approach and stages of research used in this study are Research \& Development. The EWB scale in this study has been tested by experts on guidance and counseling materials, as well as field tests to determine the acceptability of the scale in terms of scale validity and reliability.
\end{abstract}

Keywords: Scale, Emotional Well Being, Students, Covid 19 Pandemic

\begin{abstract}
ABSTRAK
Emotional Well Being (EWB) merupakan perasaan positif individu dalam menjalani kehidupan meliputi rasa bahagia dan kepuasan hidup. Pandemi covid 19 merupakan kejadian luar biasa yang berdampak bagi seluruh lini kehidupan. Pada bidang pendidikan juga tidak luput dari imbas pandemi Covid-19. Himbauan study from home yang sudah berjalan selama satu tahun lebih terus dilakukan demi menekan penyebaran kasus Covid-19. Akan tetapi, dibalik kebijakan tersebut terdapat permasalahan yang muncul tentang munculnya beberapa masalah psikologis yang dialami oleh peserta didik yang berkaitan dengan EWB. Tujuan penelitian ini adalah unuk mengembangkan skala emotional well being bagi mahasiswa di Masa Pandemi covid 19. Pendekatan dan tahapan penelitian yang digunakan dalam penelitian ini adalah Research \& Development. Skala EWB dalam penelitian ini telah dilakukan uji ahli materi bimbingan dan konseling, serta dilakukan uji lapangan untuk mengetahui keberterimaan skala dilihat dari segi validitas dan reliabilitas skala.
\end{abstract}

Kata Kunci : Skala, Emotional Well Being, Mahasiswa, Pandemi Covid 19

\section{PENDAHULUAN}

Pandemi covid 19 sudah berjalan kurang lebih satu tahun setengah. Kejadian ini merupakan kejadian luar biasa yang berdampak bagi seluruh bidang kehidupan. Tak terkecuali bidang pribadi khususnya kesehatan mental. Emotional Well Being (EWB) memiliki kaitan dengan kesehatan mental (Coverdale \& Long, 2015). Isu kesehatan mental menjadi hal yang mulai disadari urgensinya beberapa tahun terakhir.
Pada masa pandemi Covid-19, isu kesehatan mental tidak hanya penting tetapi juga menjadi kunci untuk bisa bertahan (da Silva et al., 2020).

Menyebarnya berita hoax tentang Covid-19 juga berkontribusi dalam semakin parahnya kondisi saat ini (da Silva et al., 2020). Akibatnya muncul ketakutan dan kecemasan berlebihan yang memengaruhi kondisi kesehatan mental. Pentingnya memilih sumber berita yang terverifikasi merupakan 
solusi untuk meminimalisir penyebaran berita palsu.

Himbauan study from home atau Pembelajaran Jarak Jauh (PJJ) yang sudah berjalan selama satu tahun lebih terus dilakukan demi menekan penyebaran kasus Covid-19. Akan tetapi, dibalik kebijakan tersebut terdapat permasalahan yang muncul tidak hanya tentang masalah teknis seperti kendala sinyal internet atau kuota internet, tetapi lebih dalam lagi tentang munculnya beberapa masalah psikologis yang dialami oleh peserta didik. Hal-hal tersebut berkaitan dengan kondisi EWB mahasiswa.

Mahasiswa di Perguruan Tinggi juga mengalami dampak pandemi covid 19. Menurut Hasanah, dkk. (2020) bahwa mahasiswa terdampak secara psikologis dalam pandemi saat ini. Mayoritas masalah psikologis yang dialami karena menghadapi pembelajaran daring yaitu berupa kecemasan, stres, dan depresi.

Tugas pembelajaran yang banyak sedangkan penjelasan dari dosen yang kurang dapat diterima. Penjelasan yang kurang dapat

diterima ini disebabkan oleh beberapa hal missal karena kendala teknis berupa sinyal internet atau fasilitas TIK yang kurang memadahi.

Data mengenai EWB peserta didik menjadi sangat penting untuk dilakukan. Hal tersebut demi relevannya program layanan yang akan diberikan. Penelitian ini bertujuan untuk mengembangkan skala emotional well being (EWB) untuk mahasiswa pada masa pandemi covid 19.

\section{METODE PENELITIAN}

Metode penelitian yang digunakan dalam penelitian ini adalah Research \& Development (R\&D). Proses pengembangan skala EWB berdasarkan pendapat Cohen, Swerdlik, dan Struman (2013) yang menyimpulkan ada lima tahapan pengembangan skala psikologis yaitu (1) koseptualisasi (2) konstruksi (3) uji coba (4) analisis aitem dan (5) revisi.

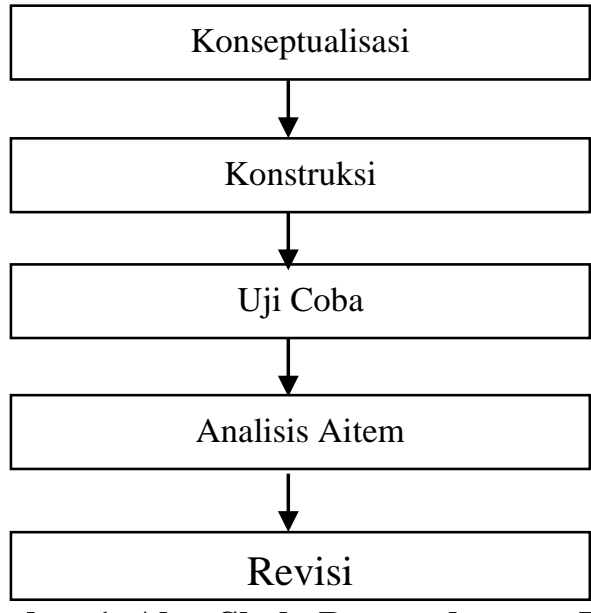

Gambar 1. Alur Skala Pengembangan EWB (Cohen, Swerdlik, dan Struman, 2013)

Pada tabel kisi-kisi skala EWB pemberian nomor pada skala memang sengaja diacak untuk menghindari responden memprediksi jawaban sehingga akan memengaruhi validitas aitem. 


\begin{tabular}{|c|c|c|c|c|}
\hline $\begin{array}{c}\text { Definisi } \\
\text { Operasional }\end{array}$ & Indikator & Prediktor & $\begin{array}{l}\text { No. } \\
\text { pada } \\
\text { skala }\end{array}$ & Aitem \\
\hline \multirow{29}{*}{$\begin{array}{l}\text { Emotional } \\
\text { Well Being } \\
\text { (EWB) adalah } \\
\text { Keadaan } \\
\text { mahasiswa } \\
\text { yang mengacu } \\
\text { kepada } \\
\text { epuasan hidup } \\
\text { secara umum } \\
\text { dan perasaan } \\
\text { positif seperti } \\
\text { kebahagiaan } \\
\text { (happiness), } \\
\text { minat dalam } \\
\text { hidup dan } \\
\text { kenikmatan } \\
\text { dalam hidup, } \\
\text { serta dapat } \\
\text { diukur dengan } \\
\text { skala EWB. }\end{array}$} & \multirow{29}{*}{$\begin{array}{l}\text { 1. Kepuasan } \\
\text { hidup secara } \\
\text { umum }\end{array}$} & \multirow{15}{*}{$\begin{array}{l}\text { 1. Diri } \\
\text { sendiri }\end{array}$} & 1 & Saya percaya diri akan tinggi badan yang saya miliki \\
\hline & & & 50 & $\begin{array}{l}\text { Saya tidak ada masalah dengan berat badan saya saat } \\
\text { ini }\end{array}$ \\
\hline & & & 49 & $\begin{array}{l}\text { Saya bersyukur karena dikaruniai kondisi fisik yang } \\
\text { lengkap }\end{array}$ \\
\hline & & & 48 & $\begin{array}{l}\text { Saya kurang memperhatikan hal-hal yang berkaitan } \\
\text { dengan kesehatan tubuh seperti berolahraga }\end{array}$ \\
\hline & & & 47 & $\begin{array}{l}\text { Saya adalah orang yang dapat menyelesaikan masalah } \\
\text { saya sendiri tanpa bantuan orang lain }\end{array}$ \\
\hline & & & 46 & $\begin{array}{l}\text { Saya kurang peka terhadap hal yang terjadi disekitar } \\
\text { saya }\end{array}$ \\
\hline & & & 45 & $\begin{array}{l}\text { Saya merasa bersemangat dalam menjalani kegiatan } \\
\text { sehari-hari }\end{array}$ \\
\hline & & & 44 & $\begin{array}{l}\text { Saya dapat merasakan apa yang dirasakan teman saat ia } \\
\text { bersedih }\end{array}$ \\
\hline & & & 43 & $\begin{array}{l}\text { Saya terkadang kurang peduli dengan teman yang } \\
\text { sedang mengalami kesusahan }\end{array}$ \\
\hline & & & 42 & $\begin{array}{l}\text { Saya menghormati teman agama lain yang sedang } \\
\text { beribadah }\end{array}$ \\
\hline & & & 41 & $\begin{array}{l}\text { Saya rasa persatuan dalam hubungan pertemanan } \\
\text { adalah penting }\end{array}$ \\
\hline & & & 40 & Dari segi ekonomi, saat ini saya merasa berkecukupan \\
\hline & & & 39 & $\begin{array}{l}\text { Saya memiliki baju yang banyak agar bisa berganti } \\
\text { pakaian setiap hari }\end{array}$ \\
\hline & & & 38 & $\begin{array}{l}\text { Saya memperhatikan jenis transportasi apa yang biasa } \\
\text { saya gunakan setiap hari }\end{array}$ \\
\hline & & & 37 & $\begin{array}{l}\text { Saya kurang senang melakukan kegiatan rekreasi saat } \\
\text { akhir pekan }\end{array}$ \\
\hline & & \multirow[t]{6}{*}{ 2. Teman } & 36 & Saya senang memiliki banyak teman \\
\hline & & & 35 & $\begin{array}{l}\text { Saya tidak bisa bergaul dengan teman yang berbeda } \\
\text { karakter dengan saya }\end{array}$ \\
\hline & & & 34 & $\begin{array}{l}\text { Saya adalah orang yang menghargai keragaman suku } \\
\text { budaya dalam lingkup pergaulan saya }\end{array}$ \\
\hline & & & 33 & $\begin{array}{l}\text { Saya bukan tipikal orang yang suka memberi bingkisan } \\
\text { pada teman sebagai tanda perhatian }\end{array}$ \\
\hline & & & 32 & Saya bersikap baik pada teman-teman saya \\
\hline & & & 31 & Teman-teman saya memperlakukan saya dengan baik \\
\hline & & \multirow{8}{*}{$\begin{array}{l}\text { 3.Lingkun } \\
\text { gan tempat } \\
\text { tinggal }\end{array}$} & 30 & Ayah saya adalah sosok panutan bagi saya \\
\hline & & & 29 & $\begin{array}{l}\text { Dukungan ayah dalam keluarga menurut saya tidak } \\
\text { terlalu penting }\end{array}$ \\
\hline & & & 28 & $\begin{array}{l}\text { Ayah membantu ibu mengerjakan pekerjaan rumah } \\
\text { tangga }\end{array}$ \\
\hline & & & 27 & $\begin{array}{l}\text { Ibu saya selalu mendukung setiap kegiatan yang saya } \\
\text { lakukan }\end{array}$ \\
\hline & & & 26 & $\begin{array}{l}\text { Ibu saya jarang menghubungi ketika saya sedang tidak } \\
\text { berada dirumah }\end{array}$ \\
\hline & & & 25 & Ibu selalu mendengarkan ketika saya ingin bercerita \\
\hline & & & & 75 \\
\hline & & & 24 & Saya kurang akur dengan saudara-saudara saya \\
\hline
\end{tabular}




\begin{tabular}{|c|c|c|c|}
\hline & & & dirumah \\
\hline & & 23 & Keluarga adalah prioritas bagi saya \\
\hline & & 22 & Rumah adalah tempat ternyaman bagi saya \\
\hline & & 21 & letak rumah tiidak selalu menentukan keberuntungan \\
\hline & & 20 & $\begin{array}{l}\text { kondisi tempat tinggal menentukan kesejahteraan } \\
\text { keluarga }\end{array}$ \\
\hline & & 19 & $\begin{array}{l}\text { Tetangga terkadang mengirim makanan apabila ada } \\
\text { hajatan }\end{array}$ \\
\hline & & 18 & $\begin{array}{l}\text { Tetangga rumah sering membuat kegaduhan yang } \\
\text { membuat saya kurang nyaman }\end{array}$ \\
\hline & & 17 & Saya memiliki tetangga rumah yang baik \\
\hline & 4. & 16 & Internet wifi dikampus saya sering macet \\
\hline & Pendidikan & 15 & $\begin{array}{l}\text { Petugas perpustakaan dikampus saya kurang membantu } \\
\text { saat saya kesusahan mencari buku }\end{array}$ \\
\hline & & 14 & $\begin{array}{l}\text { Dosen saya memberikan pengalaman belajar yang baik } \\
\text { selama kuliah }\end{array}$ \\
\hline & & 13 & Admin prodi saya orangnya ramah \\
\hline & & 12 & $\begin{array}{l}\text { Saya puas dengan system perkuliahan dikampus saat } \\
\text { ini }\end{array}$ \\
\hline & & 11 & $\begin{array}{l}\text { Biaya kuliah saya sesuai dengan kondisi keuangan } \\
\text { keluarga saya }\end{array}$ \\
\hline \multirow{10}{*}{$\begin{array}{l}\text { 2. Perasaan } \\
\text { Positif } \\
\text { (Positive } \\
\text { Affection) }\end{array}$} & \multirow{3}{*}{$\begin{array}{l}1 . \\
\text { Kebahagia } \\
\text { an } \\
\text { (happiness } \\
\text { ) }\end{array}$} & 10 & Saya senang dalam kondisi keluarga saya saat ini \\
\hline & & 9 & $\begin{array}{l}\text { Saya tidak mengikuti kegiatan lain dikampus selain } \\
\text { kuliah }\end{array}$ \\
\hline & & 8 & $\begin{array}{l}\text { Saya aktif dalam kegiatan di lingkungan tempat saya } \\
\text { tinggal }\end{array}$ \\
\hline & \multirow{4}{*}{$\begin{array}{l}\text { 2. Minat } \\
\text { dalam } \\
\text { hidup } \\
\text { (Interest in } \\
\text { life) }\end{array}$} & 7 & Saya bersemangat untuk belajar dan kuliah \\
\hline & & 6 & Saya ingin segera lulus kuliah dan bekerja \\
\hline & & 5 & $\begin{array}{l}\text { Saya selalu menjadwalkan kegiatan refreshing setiap } \\
\text { bulan }\end{array}$ \\
\hline & & 4 & Saya kurang mengikuti trend berpakaian saat ini \\
\hline & 3. & 3 & \\
\hline & $\begin{array}{l}\text { Kenikmata } \\
\text { n dalam } \\
\text { hidup }\end{array}$ & & Saya adalah orang yang cukup religius \\
\hline & & 2 & Saya pribadi yang senang bersosialisasi \\
\hline
\end{tabular}

Tabel 1. Kisi-kisi EWB sebelum EWB 


\section{HASIL DAN PEMBAHASAN \\ HASIL}

Pengembangan skala EWB juga dilakukan uji ahli untuk menentukan validitas konstrak. Validitas konstrak dapat diartikan sejauhmana definisi operasional (dalam bentuk indikator keperilakuan) memang mencerminkan konstrak yang hendak diukur (Decoster; Altermatt dalam Azwar, 2015). Peneliti melakukan uji ahli atau expert judgement pada Ibu Laelatul Arofah, M.Pd. Beliau adalah Dosen Bimbingan dan Konseling Universitas Nusantara PGRI Kediri.

Aspek yang dinilai oleh uji ahli meliputi aspek materi, konstruksi, dan kebahasaan. Aspek materi terdiri dari kesesuaian pernyataan dengan indikator EWB, kejelasan batasan pernyataan, sehingga tidak ambigu, kesesuaian isi materi dalam pernyataan dengan petunjuk pengukuran, jenjang, jenis sekolah dan tingkat kelas. Aspek konstruksi terdiri dari kejelasan dan kelugasan perumusan pokok pernyataan, kejelasan petunjuk pengisian, kejelasan rumusan kalimat soal atau pertanyaan. aspek kebahasaan terdiri dari kebakuan penggunaan tata bahasa dalam pernyataan, Penggunaan kata-kata/istilah yang berlaku umum, kekomunikatifan rumusan kalimat pertanyaan.

Terdapat dua data hasil penilaian uji ahli yaitu data kuantitatif dan kualitatif. Data kuantitatif menunjukkan skor 30 pada hasil penilaian ahli. Penilaian skala secara umum juga menunjukkan bahwa skala dalam kategori LD atau Layak Digunakan. Adapun hasil penilaian uji ahli secara kualitatif adalah sebagai berikut.

Tabel 2. Saran, Masukan, dan Revisi Berdasarkan Masukan Uji Ahli

\begin{tabular}{|c|c|c|}
\hline Ahli & $\begin{array}{c}\text { Saran dan masukan } \\
\text { ahli }\end{array}$ & $\begin{array}{c}\text { Hal yang } \\
\text { dilakukan } \\
\text { peneliti }\end{array}$ \\
\hline $\begin{array}{l}\text { Laelatul } \\
\text { Arofah, } \\
\text { M.Pd. }\end{array}$ & $\begin{array}{lr}\text { Saran } & \text { pada } \\
\text { penomoran } & \text { agar } \\
\text { pengacakan } & \text { nomor } \\
\text { lebih } & \text { random } \\
\text { kembali } & \text { untuk } \\
\text { mencegah } & \\
\text { responden } & \text { dapat } \\
\text { dengan } & \text { mudah }\end{array}$ & $\begin{array}{l}\text { Nomor } \\
\text { pada skala } \\
\text { setelah uji } \\
\text { validitas } \\
\text { dan } \\
\text { reliabilitas } \\
\text { telah } \\
\text { diacak }\end{array}$ \\
\hline
\end{tabular}

$$
\begin{aligned}
& \text { menebak } \\
& \text { pernyataan/jawaban } \\
& \text { selanjutnya. }
\end{aligned}
$$

\section{Uji Validitas}

Uji validitas dilakukan untuk mengetahui apakah skala mampu menghasilkan data yang akurat sesuai dengan tujuan ukurnya (Azwar, 2015). Dari pendapat tersebut, maka uji validitas dalam penelitian ini adalah untuk mengetahui apakah skala EWB memang mengukur apa yang ingin diketahui yaitu kondisi emotional well being mahasiswa.

Tabel 3. Hasil Validitas Skala EWB

\begin{tabular}{cccc}
\hline $\begin{array}{c}\text { No. } \\
\text { aitem }\end{array}$ & r hitung & r tabel & Keterangan \\
\hline 1 & 0.281 & 0.361 & Tidak Valid \\
\hline 50 & 0.424 & 0.361 & Valid \\
\hline 49 & -0.017 & 0.361 & Tidak Valid \\
\hline 48 & 0.323 & 0.361 & Tidak Valid \\
\hline 47 & 0.532 & 0.361 & Valid \\
\hline 46 & 0.416 & 0.361 & Valid \\
\hline 45 & 0.377 & 0.361 & Valid \\
\hline 44 & 0.440 & 0.361 & Valid \\
\hline 43 & 0.076 & 0.361 & Tidak Valid \\
\hline 42 & 0.451 & 0.361 & Valid \\
\hline 41 & 0.587 & 0.361 & Valid \\
\hline 40 & -0.018 & 0.361 & Tidak Valid \\
\hline 39 & 0.409 & 0.361 & Valid \\
\hline 38 & 0.340 & 0.361 & Tidak Valid \\
\hline 37 & -0.050 & 0.361 & Tidak Valid \\
\hline 36 & 0.645 & 0.361 & Valid \\
\hline 35 & 0.432 & 0.361 & Valid \\
\hline 34 & 0.292 & 0.361 & Tidak Valid \\
\hline 33 & 0.361 & 0.361 & Tidak Valid \\
\hline 32 & -0.255 & 0.361 & Tidak Valid \\
\hline 31 & 0.579 & 0.361 & Valid \\
\hline 30 & 0.692 & 0.361 & Valid \\
\hline 29 & 0.602 & 0.361 & Valid \\
\hline 28 & 0.631 & 0.361 & Valid \\
\hline 27 & 0.396 & 0.361 & Valid \\
\hline 26 & 0.608 & 0.361 & Valid \\
\hline 25 & -0.112 & 0.361 & Tidak Valid \\
\hline 24 & 0.401 & 0.361 & Valid \\
\hline 23 & 0.352 & 0.361 & Tidak Valid \\
\hline 22 & 0.340 & 0.361 & Tidak Valid \\
\hline 21 & 0.454 & 0.361 & Valid \\
\hline 20 & 0.057 & 0.361 & Tidak Valid \\
\hline 19 & 0.423 & 0.361 & Valid \\
\hline 18 & 0.635 & 0.361 & Valid \\
\hline 17 & 0.635 & 0.361 & Valid \\
\hline & & & \\
\hline 45 &
\end{tabular}




\begin{tabular}{cccc}
\hline 16 & 0.490 & 0.361 & Valid \\
\hline 15 & 0.490 & 0.361 & Valid \\
\hline 14 & -0.036 & 0.361 & Tidak Valid \\
\hline 13 & 0.577 & 0.361 & Valid \\
\hline 12 & 0.532 & 0.361 & Valid \\
\hline 11 & 0.473 & 0.361 & Valid \\
\hline 10 & 0.388 & 0.361 & Valid \\
\hline 9 & 0.404 & 0.361 & Valid \\
\hline 8 & 0.361 & 0.361 & Valid \\
\hline
\end{tabular}

\begin{tabular}{cccc}
\hline 7 & 0.637 & 0.361 & Valid \\
\hline 6 & 0.654 & 0.361 & Valid \\
\hline 5 & -0.118 & 0.361 & Tidak Valid \\
\hline 4 & 0.547 & 0.361 & Valid \\
\hline 3 & 0.480 & 0.361 & Valid \\
\hline 2 & 0.458 & 0.361 & Valid \\
\hline
\end{tabular}

Definisi operasional

Keadaan

mahasiswa

yang mengacu

kepada

kepuasan

hidup secara

umum dan

perasaan

positif seperti

kebahagiaan

(happiness),

minat dalam

hidup dan

kenikmatan

dalam hidup.

\section{Tabel 4. Kisi-kisi EWB Setelah Melalui Pengujian}

$$
\text { Indikator Prediktor No. Aitem }
$$

$\begin{array}{ll}\text { 1. kepuasan } & \text { 1. Diri } \\ \text { hidup } & \text { sendiri } \\ \text { secara } & \\ \text { umum } & \end{array}$

13 Saya tidak ada masalah dengan berat badan saya saat ini

22 Saya adalah orang yang dapat menyelesaikan masalah saya sendiri tanpa bantuan orang lain

$1 \quad$ Saya kurang peka terhadap hal yang terjadi disekitar saya

11 Saya merasa bersemangat dalam menjalani kegiatan sehari-hari

17 Saya dapat merasakan apa yang dirasakan teman saat ia bersedih

21 Saya menghormati teman agama lain yang sedang beribadah

2 Saya rasa persatuan dalam hubungan pertemanan adalah penting

$5 \quad$ Saya memiliki baju yang banyak agar bisa berganti pakaian setiap hari

\begin{tabular}{lcl}
\hline \multicolumn{1}{c}{$\begin{array}{l}2 . \\
\text { Teman }\end{array}$} & 12 & Saya senang memiliki banyak teman \\
\cline { 2 - 3 } & 30 & $\begin{array}{l}\text { Saya tidak bisa bergaul dengan teman } \\
\text { yang berbeda karakter dengan saya }\end{array}$ \\
\cline { 2 - 3 } $\begin{array}{l}\text { Lingkunga } \\
\text { n tempat } \\
\text { tinggal }\end{array}$ & $\begin{array}{l}\text { Teman-teman saya memperlakukan saya } \\
\text { dengan baik }\end{array}$ & Ayah saya adalah sosok panutan bagi saya \\
\cline { 2 - 3 } & 14 & $\begin{array}{l}\text { Dukungan ayah dalam keluarga menurut } \\
\text { saya tidak terlalu penting }\end{array}$ \\
\cline { 2 - 3 } & 19 & $\begin{array}{l}\text { Ayah membantu ibu mengerjakan } \\
\text { pekerjaan rumah tangga }\end{array}$ \\
\cline { 2 - 3 } & 20 & $\begin{array}{l}\text { Ibu saya selalu mendukung setiap } \\
\text { kegiatan yang saya lakukan }\end{array}$ \\
& $\begin{array}{l}\text { Ibu saya jarang menghubungi ketika saya } \\
\text { sedang tidak berada dirumah }\end{array}$ \\
\hline 15 & $\begin{array}{l}\text { Saya kurang akur dengan saudara-saudara } \\
\text { saya dirumah }\end{array}$ \\
\hline 7 & $\begin{array}{l}\text { letak rumah tiidak selalu menentukan } \\
\text { keberuntungan }\end{array}$ \\
\hline 9 & $\begin{array}{l}\text { Tetangga terkadang mengirim makanan } \\
\text { apabila ada hajatan }\end{array}$ \\
\hline
\end{tabular}


33 Tetangga rumah sering membuat kegaduhan yang membuat saya kurang nyaman

\begin{tabular}{|c|c|c|c|}
\hline & \multirow{7}{*}{$\begin{array}{c} \\
4 . \\
\text { Pendidikan }\end{array}$} & \multirow{3}{*}{$\frac{34}{10}$} & \\
\hline & & & Saya memiliki tetangga rumah yang baik \\
\hline & & & Internet wifi dikampus saya sering macet \\
\hline & & 24 & $\begin{array}{l}\text { Petugas perpustakaan dikampus saya } \\
\text { kurang membantu saat saya kesusahan } \\
\text { mencari buku }\end{array}$ \\
\hline & & 29 & Admin prodi saya orangnya ramah \\
\hline & & 27 & $\begin{array}{l}\text { Saya puas dengan system perkuliahan } \\
\text { dikampus saat ini }\end{array}$ \\
\hline & & 16 & $\begin{array}{l}\text { Biaya kuliah saya sesuai dengan kondisi } \\
\text { keuangan keluarga saya }\end{array}$ \\
\hline $\begin{array}{l}2 . \\
\text { Perasaan }\end{array}$ & $\begin{array}{c}1 . \\
\text { Kebahagia }\end{array}$ & 31 & $\begin{array}{l}\text { Saya senang dalam kondisi keluarga saya } \\
\text { saat ini }\end{array}$ \\
\hline $\begin{array}{l}\text { Positif } \\
\text { (Positive }\end{array}$ & $\begin{array}{l}\text { an } \\
\text { (happiness) }\end{array}$ & 23 & $\begin{array}{l}\text { Saya tidak mengikuti kegiatan lain } \\
\text { dikampus selain kuliah }\end{array}$ \\
\hline Affection) & & 32 & $\begin{array}{l}\text { Saya aktif dalam kegiatan di lingkungan } \\
\text { tempat saya tinggal }\end{array}$ \\
\hline & $\begin{array}{l}\text { 2. Minat } \\
\text { dalam }\end{array}$ & 18 & $\begin{array}{l}\text { Saya bersemangat untuk belajar dan } \\
\text { kuliah }\end{array}$ \\
\hline & hidup & 25 & Saya ingin segera lulus kuliah dan bekerja \\
\hline & $\begin{array}{l}\text { (Interest in } \\
\text { life) }\end{array}$ & 6 & $\begin{array}{l}\text { Saya kurang mengikuti trend berpakaian } \\
\text { saat ini }\end{array}$ \\
\hline & 3. & 28 & \\
\hline & $\begin{array}{l}\text { Kenikmata } \\
\mathrm{n} \text { dalam } \\
\text { hidup }\end{array}$ & & Saya adalah orang yang cukup religius \\
\hline & & 26 & Saya pribadi yang senang bersosialisasi \\
\hline
\end{tabular}

\section{Uji Reliabilitas}

Pada skala EWB juga dilakukan uji reliabilitas. Uji reliabilitas digunakan untuk mengukur konsistensi instrument yang merupakan indikator dari variabel atau konstruk. Instrumen dikatakan reliabel apabila nilai Cronbach's Alpha > 0,60.

\section{Tabel 5. Uji Reliabilitas}

\begin{tabular}{|c|c|}
\hline \multicolumn{2}{|c|}{ Reliability Statistics } \\
\hline $\begin{array}{c}\text { Cronbach's } \\
\text { Alpha }\end{array}$ & $\mathrm{N}$ of Items \\
\hline .876 & 50 \\
\hline
\end{tabular}

Dari tabel didapatkan bahwa nilai Cronbach's alpha $>0,60$ yaitu sebesar 0,876 . Nilai tersebut menunjukkan bahwa skala EWB reliabel.

\section{PEMBAHASAN}

Setelah penjabaran hasil uji validitas dan reliabilitas beserta hasil uji konstruk oleh ahli, maka didapatkan bahwa terdapat dua indikator yang digunakan sebagai dasar pengembangan instrumen yaitu kepuasan hidup dan perasaan positif atau positive affection. Indikator tersebut dikembangkan dari teori Langeland (2014), bahwa EWB merupakan kondisi dimana individu merasakan kepuasan dalam hidup atau life satisfaction dan memiliki perasaan positif atau positive affection.

Kepuasan dalam hidup atau life satisfaction didefinisikan sebagai kepuasan akan kehidupan yang dijalani meliputi pribadi dan lingkungan sekitar. Menurut Seligman (2002), kepuasan hidup juga tampak pada 
perasaan puas akan hidupnya dimasa lalu,bahagia di masa kini, dan optimis akan masa depan. Sedangkan positive affection atau memiliki perasaan positif termasuk didalamnya adalah perasaan bahagia atau happiness, minat dalam hidup atau interest in life, dan kenikmatan dalam hidup. Lebih lanjut, perasaan positif menurut Langeland (2014) termasuk didalmnya keceriaan, semangat, kebahagiaan, ketenangan, kedamaian, merasa puas, serta memaknai kehidupan dengan baik.

Menurut World Health Organization (WHO, 2012), EWB merupakan suatu keadaan sejahtera dimana individu menyadari kemampuan mereka sendiri, dapat mengatasi tekanan dalam hidup, bekerja secara produktif, dan bermanfaat serta mampu memberikan kontribusi terhadap masyarakat. EWB meruapakan keadaan yang diinginkan oleh setiap individu agar merasakan kebahagiaan. Tetapi tentu saja mencapai kondisi ini tidak lepas dari pengaruh banyak hal.

Pada masa pandemi covid 19, tingkat EWB mahasiswa juga terdampak. Tidak hanya masalah dengan dirinya pribadi tetapi juga interaksi dengan lingkungan. Kaitanya dengan pembelajaran dikampus, mahasiswa mengalami kejenuhan belajar. Herdiana () menjelaskan bahwa permasalahan bagi mahasiswa saat ini adalah mengenai adaptasi perkuliahan daring yang tidak selalu berjalan lancar. Disebutkan bahwa mahasiswa yang sebelumnya tidak pernah melakukan kegiatan pembelajaran daring menjadi kurang siap dalam hal persiapan dan penguasaan TIK.

Kelebihan penelitian ini adalah untuk mendapatkan data yang terkait dengan tingkat EWB mahasiswa pada masa pandemi covid 19. Hal tersebut dapat dijadikan dasar untuk melakukan penelitian selanjutnya berupa pengkondisian EWB mahasiswa menggunakan treatment tertentu dalam teknik penelitian yang lain. Selain kelebihan tersebut, kelebihan lain adalah instrumen dalam penelitian ini telah dikembangkan melalui landasan teori yang kuat dan pernyataan yang disusun sudah disesuaikan dengan kondisi mahasiswa saat ini.
Keterbatasan penelitian ini adalah jumlah responden untuk mendapatkan data guna uji validtas dan reliabilitas masih terbatas hanya 30 siswa saja. Meskipun sudah memenuhi syarat, akan tetapi lebih baik jumlah responden lebih dari jumlah tersebut agar tingkat validitas instrumen dapat lebih baik lagi.

\section{KESIMPULAN}

Kesimpulan penelitian ini adalah skala EWB dapat dijadikan alat ukur emotional well being mahasiswa pada masa pandemi covid 19. Hal tersebut didapatkan dari hasil analisis uji validitas dan reliabilitas serta data uji ahli sebagai dasar uji validitas konstruk. Selanjutnya instrument penelitian ini dapat dimanfaatkan sebagai alat ukur penelitian dengan variabel EWB. Selain itu, penelitian ini dapat dijadikan dasar dalam desain penelitian yang lain.

\section{REFERENSI}

Azwar, S. (2014). Penyusunan Skala Psikologis. Yogyakarta: Pustaka Pelajar https://doi.org/https://doi.org/10.32698/2 5275

Coverdale, G. E., \& Long, A. F. (2015). Emotional wellbeing and mental health: An exploration into health promotion in young people and families. In Perspectives in Public Health (Vol. 135, Issue

$1)$. https://doi.org/10.1177/17579139145580 80

Cohen, R. J., Swerdlik, M.E., \& Sturman, E.D. (2013). Psychological testing and assessment: Introduction to test and measurement. New York: McGraw-Hill Education

da Silva, A. G., Miranda, D. M., Diaz, A. P., Teles, A. L. S., Malloy-Diniz, L. F., Palha, A. P., \& Faillace, L. A. (2020). Mental health: Why it still matters in the midst of a pandemic. Brazilian Journal of Psychiatry, 42(3), 229-231. https://doi.org/10.1590/1516-4446-2020$\underline{0009}$

Hasanah, U., Ludiana, L., Immawati, I., \& Livana, P. H. (2020). Psychological 
Description of Students in the Learning Process During Pandemic Covid-19. Jurnal Keperawatan Jiwa, 8(3), 299306.https://doi.org/10.26714/jkj.8.3.2020 .299-306

Herdiana, D., Rudiana, R., \& Supriatna, S. (2021). Kejenuhan Mahasiswa dalam Mengikuti Perkuliahan Daring dan Strategi Penanggulangannya. Edunesia: Jurnal Ilmiah Pendidikan, 2(1). https://doi.org/10.51276/edu.v2i1.128

Langeland, E. (2014). Emotional Well-Being. Cmaj, $\quad$ 1874-1876.

https://doi.org/10.1007/978-94-0070753-5

Livana, P. H., Mubin, M. F., \& Basthomi, Y. (2020). "Learning Task" Attributable to Students' Stress During the Pandemic Covid-19. Jurnal Ilmu Keperawatan Jiwa, 3(2), 203-208. http://dx.doi.org/10.32584/jikj.v3i2.590

Seligman, M. (2002). Authentic Happiness: Using The New Positive Psycholoy to Realize Your Potential for Lasting Fulfillment. The American Journal of Psychiatry, 161(5), 936-937. https://doi.org/10.7748/ns.2.28.34.s65

World Health Organization. (2012). Adolescent mental health: mapping actions of nongovernmental organizations and other international development organizations. WHO Press. 